ORIGINAL ARTICLE

AFRICAN JOURNAL OF CLINICAL AND EXPERIMENTAL MICROBIOLOGY AJCEM/201179/21203

COPYRIGHT 2012

AFR. J. CLN. EXPER. MICROBIOL 13(2): 94-98 http://dx.doi.org/10.4314/ajcem.v13i2.7

\title{
REPRODUCTIVE HEALTH ISSUES AND INCIDENCE OF SOME REPRODUCTIVE TRACT INFECTIONS AMONG MUSLIM WOMEN IN PURDAH IN JOS-NIGERIA
}

\author{
K.B. Tanyigna ${ }^{1}$; J.K Tanyigna ${ }^{2}$; F. Aremu ${ }^{3}$ \& J. O. Adisa ${ }^{4}$ \\ ${ }^{1}$ Department of Research, The National Institute, Kuru, P.M.B. 2084, Bukuru, Plateau State, Nigeria. ${ }^{2}$ Departments \\ of Sociology; ${ }^{3}$ Microbiology; ${ }^{4}$ Medical Laboratory Science, University of Jos, \\ P.M.B. 2084 Jos- Nigeria.
}

Correspondence: Dr. K. B. Tanyigna

\begin{abstract}
Candidiasis and Trichomoniasis are the commonest Reproductive Tract Infections (RTIs) amongst women in purdah in the capital city of Jos- Nigeria. Majority of these women $(>68 \%)$ have primary education as the highest educational qualification and majority of them (>92\%) are full time house wives. The study has also revealed that there is a high level $(57 \%)$ delay in seeking for reproductive health needs, which were only remedied due to persistence of symptoms. This gives us the inference as to the myriad of sequalae that might have resulted in cases of asymptomatic RTIs. The most reproductive health needs of women in purdah are inadequate facilities in clinics/hospitals. This factor as well as other factors such as poor education, unilateral decision making by some men in purdah in matters of reproductive needs, misunderstanding and misinterpretation of the Qu'ran have immensely contributed to the increasing cases of RTIs among these women. These problems can be reduced to the minimum by educating both the men and the women in purdah with the best medium being the radio/television programs.
\end{abstract}

KEY WORDS: Purdah, Reproductive Health, Infection, Women.

\section{INTRODUCTION}

Purdah is the practice of seclusion and veiling among women. This practice is seen mostly among the Muslim. This custom is however shared by the Hindus and Muslims in what is usually considered the Purdah zone. This zone comprises Bangladesh, Pakistan and India. The purposes for the practice among these two religions are different. For the Muslims the purpose is to safeguard their women from view outside the family and to keep them in their own separate feminine world for the purpose of maintaining fidelity $(1,2)$. In stating the reasons for the need of purdah, the Qu'ran declares that "the observance (of hijab is so that the (pure and pious women) may be recognized and not be molested" (3).

Increasing number of Muslim women in purdah in Jos, the capital of Plateau State in Nigeria have been noticed visiting hospitals and clinics with chronic cases of Reproductive Tract Inflections (RTIs) or Sexually Transmissible Diseases (STDs) are the reasons for the chronic infections related to restrictions of movements placed on these women? Or are they related to the decision making process? Answers to these questions and many others are attempted in the cause of this study.

Motivation is an entity that compels one to action of a particular type, $\mathrm{i}$ a desire that precedes an act and determines it (4). From the instinctive point of view, it means that motivation consists of energy generation and direction guiding processes which together produce all forms of human behavior. Health - care seeking motivation is therefore the desire to seek for health. This involves the drive as to why, and the mechanism as to how one goes about seeking for health care (5). The outcome of these complex systems of motives or motivations is human behavior (6). If purdah women now go to seek for health care in spite of the restrictions on movement hence these increasing visitations to hospitals and clinics, several motives may be responsible for these compelling actions. The woman may want to be cured of the disease, or may be aware of the risk, or may even want to be adorned by her husband. There may be several other reasons which this study is aimed at highlighting.

Reproductive Tract Inflections can be sexually transmitted or non-sexually transmitted but have grave sequalae especially if untreated. These sequalae include: Pelvic Inflammatory Disease, spontaneous abortion and still birth, low birth weight, congenita1 infection, ectopic pregnancy, infant blindness and mental retardation $(7,8,9,10)$. Among the non pregnant women the sequalae include: cancers (11); infertility in about $50-80 \%(12)$ and genital infections is said to result to $90 \%$ maternal death in developing countries (13).

The incidences of some of these RTIs have also been studied in comparison to women not in purdah practice. This is because RTIs do not only bring about medical problems but they also constitute social and economic problems in Nigeria not only among urban dwellers but in the rural areas as well (14). Gonorrhea, Syphilis and now HIV/AIDs are the most widely known RTIs/STDs but there are more than twenty others. On the average, an estimated 685,000 people are infected daily with these diseases and every year there are about 250 million new cases (15). 


\section{MATERIALS AND METHODS}

Selection of subjects and Specimen Collection

After an official permission had been sought and obtained from Shifa hospital in Jos, 85 women in purdah visiting the hospital with suspected cases of RTIs were examined and high vaginal swabs (HVS) were collected by the Medical Officer from the upper third wall of the vagina with a sterile swab stick. The swab was rotated gently against the vagina wall. This was after a sterile moistened speculum had been inserted into the vagina to expose the cervix. Specimen collection was limited to HVS so as to limit the scope of the research.

Inoculation of samples

Specimen was applied to a small area of the prepared (MacConkey, Chocolate and Sabouraud) agar plates to make wells. A flame sterilized wire loop was then used to spread the innoculum to ensure single colonies and incubated for 24 hours at $37^{\circ} \mathrm{C}$.

\section{Preparation of wet smears}

A sample of the exudates on the swab stick was transferred on a clean glass slide and a drop of physiological saline was added and mixed properly to make a thin preparation. This was covered with a cover slip and then examined under the microscope using $x 10$ and $x 40$ objectives of the microscope. This method was aimed at identifying parasites and protozoan RTIs according to Cheesbrough (16).

\section{Gram Staining of Smears}

After labeling the clean slide with patients name and date, the swab containing the specimen was then rolled on the clean slide and spread evenly covering an area of about $15 \mathrm{~mm}$ in diameter to make a smear. The smear was left in a safe place to air-dry and then passed through a burning flame three times and allowed to cool. The slide was then laid on a staining rack and covered with crystal violet stain for 60 minutes and rapidly washed off with clean water. The water was tipped from the slide and the smear covered with Lugol's iodine for 60 seconds and washed off. Afterwards the smear was decolourised rapidly with acetone and washed off immediately. The smear was then covered with neutral red for 2 minutes and washed off with water. The slide was finally placed on a staining rack to air- dry before being viewed using x40 and x100 objectives of the microscope.

\section{Vaginal fluid $\mathrm{pH}$ and whiff (Amine) Tests}

The $\mathrm{pH}$ paper was placed on the surface of the speculum after it had been removed from the vagina and the $\mathrm{pH}$ read, while the vaginal malodor was used to diagnose Gardnerella vaginosis. The method included the release of "fishy" amines from the vaginal fluid after the addition of $10 \%$ potassium hydroxide $(\mathrm{KOH})$. Swabs containing vaginal fluid were rolled on clean slides and $\mathrm{KOH}$ were added.

\section{Structured in-depth Interview}

A structured questionnaire (appendix 1) was administered on each of the women involved in the study to collect various data on Health-seeking motivations, Reproductive health needs, Decision making process and the knowledge of RTIs among women in purdah.

\section{RESULTS}

The incidence rates of RTIs among the 85 respondents were as follows:

Candida sp had 75 (88.2\%); Trichomonas vaginalis with $3(3.7 \%)$ and Gardnerella vaginalis with $2(2.4 \%)$. There were no infection in $5(5.9 \%)$ of the cases (Table I). Similarly the age distribution showed that age group 21- 30 attended the hospital most with suspected cases of RTIs. This age group had $68(80 \%)$ cases (Table 1).

\section{TABLE 1: RTIS AMONG DIFFERENT AGE GROUPS OF WOMEN IN PURDAH VISITING THE HOSPITAL}

WITH SYMPTOMS OF RTIs

$\begin{array}{lllll}\text { Age group/RTI } & 11-20(\%) & 21-30(\%) & 31-40(\%) & \text { Total(\%) } \\ \text { Candida spp } & 8(9.4) & 58(68.2) & 9(10.6) & 75(88.2) \\ \text { Trichmonas vaginalis } & 0(0) & 3(3.5) & 0(0) & 3(3.5) \\ \text { Gardnerella vaginalis } & 0(0) & 2(2.4) & 0(0) & 2(2.4) \\ \text { No infection } & 0(0) & 5(5.9) & 0(0) & 5(5.9) \\ \text { Total } & 8(9.4) & 68(80) & 9(10.6) & 85(100)\end{array}$


TABLE 2: MARITAL STATUS OF WOMEN IN PURDAH VISITING THE HOSPITAL WITH SYMPTOMS OF RTIS

\begin{tabular}{lllll}
\multicolumn{1}{c}{ RTI } & Married (\%) & Divorced(\%) & Single(\%) & Total(\%) \\
Candida spp & $71(83.5)$ & $2(2.35)$ & $2(2.4)$ & $75(88.2)$ \\
Trichomonas vaginalis & $3(3)$ & $0(0)$ & $0(0)$ & $3(3.5)$ \\
Gardnerella vaginalis & $2(2.4)$ & $0(0)$ & $0(0)$ & $2(2.4)$ \\
No infection & $4(4.7)$ & $1(1.27)$ & $0(0)$ & $5(5.9)$ \\
Total & $80(94.1)$ & $3(3.5)$ & $2(2.4)$ & $85(100)$
\end{tabular}

Table 3: Educational status of women in purdah

visiting the hospital with symptoms of RTIs

\begin{tabular}{lll} 
Highest Education & \multicolumn{2}{c}{ No $(\%)$} \\
Primary & 58 & $(8.2)$ \\
Secondary & 16 & $(18.8)$ \\
Tertiary & 2 & $(2.4)$ \\
Qur'anic & 8 & $(9.4)$ \\
No formal education & 1 & $(1.2)$ \\
Total & 85 & $(100)$
\end{tabular}

Table 2 showes that $80(94.1 \%)$ of the respondents were married while $3(3.5 \%)$ were divorced and 2 $(2.4 \%)$ were single. Most of these women $(68.2 \%)$ had their educational status at the primary level (Table 3). So also were most of the women $(92.9 \%)$ full time house wives (Table 4 ).

At the earliest notice of symptoms of RTIs a total of 49 $(57.6 \%)$ of these cases delayed between the periods of less than 1 month and more than 1 year before presenting to the hospital, while 36 (42.4) presented their cases at the earliest noticed of the symptoms although $89.8 \%$ of those that delayed were not aware of the risk involved in the delay. Others who were aware of the risk but delayed going to hospitals were on the basis that they went to traditional healers or administered self treatment. On the other hand those that did not delay in having prompt treatment after noticing the symptoms because they were aware of the risks were $13(36.1 \%)$.

There are several reproductive health needs of these women but the most (i.e $51.76 \%$ ) being the lack of adequate facilities for these women followed by the issue of abortion and miscarriage of pregnancies with $18.82 \%$. The best ways in which decision making process can be altered in favour of these women in purdah appears to be by educating both women in purdah and their husbands. This method of education is suggested by $89.4 \%$ of these women. Similarly $48.2 \%$ and $45.1 \%$ of these women have suggested that they can best he educated on matters that have to do

with RTIs through Radio/Television and Health personnel respectively.

\section{DISCUSSION}

The Reproductive Tract Infections (RTIs) with the highest rates in the present study are Candidiasis and Trichomoniasis which is in agreement with the work of Ogunbanjo (14) who worked in the Northern and Southern parts of Nigeria. However, the work of Wasserheit (17) showed Gonorrhea to be the commonest RTI in African countries. The difference in the findings may not be unrelated to the fact that diagnostic procedures in the present study were bias against gonorrhea due to the limitation of materials. The high rate of Candidiasis in purdah and indeed our community could be understood if factors which favour the growth of Candidiasis such as use of scented soaps, poor hygiene, and vaginal disinfectant are seen to also have high rates in our community.

The high incidences rates of trichomoniasis may also be understood against the background that most of it is asymptomatic in women (11) although it is clinically indicated by severe itching and painful sexual intercourse.

Majority of purdah women as reflected in the present study showed that their highest level of education is the primary $(68.20 \%)$ as well as the fact that majority were full time house wives with low income (92.90\%). This does not come as a surprise because education in the core north has been focused mainly on men due to religion and social community sanctions (18). Again since girls at the age of 12 and 13 could be given out to marriage coupled with the fact that purdah reduces female mobility.

The low level of education in purdah can also be related to the high percentage $(57 \%)$ of puriah women who delay seeking for health care in matters of RTLs as well as their poor sanity. Sufficient education could have made for the sequalae of the infections and adequate sanity precautions not only to been known but also taken rather than going to traditional healers and use of hot water to cure RTIs. This is also why the motivating factors for eventually seeking for reproductive health were the persistence of symptoms. 
The low socio-economic status of the women in purdah as manifested in this study is also a suggestion as to why these women do not plan for the children to bear and are not knowledgeable about RTIs. This has equally had effect on the spread and the chronic state of RTIs because they share the toilets and bathrooms.

As a result of the fact that Nigerians from the northern part are good listeners of radio / television programmes, this means of communication is here by suggested as a way through which women in purdah can be educated on reproductive health matters. This has also been reflected by the suggestions of the women in the structured interview questionnaires. The greatest reproductive health need of women in purdah as revealed in this study has to do with inadequate facilities in clinics/hospitals. Adequate facilities would make these women feel comfortable. This is because when women fell that they have a secured environment, they are likely to reveal much more information about themselves. This is agreed by Oomman (19) who stated that other equally important issues are usually missing in reproductive health literature. Oomman (19) further stated that sexuality is a reflection of a complex phenomenon with a comprehensive list of elements.

TABLE 4: OCCUPATIONAL STATUS OF WOMEN IN PURDAH VISITING THE HOSPITAL WITH SYMPTOMS OF RTIS

\begin{tabular}{|c|c|c|c|c|c|}
\hline & Full time & Business & Civil & Student & Total \\
\hline RTI & House wife & woman & Servant (\%) & (\%) & $(\%)$ \\
\hline Candida spp & $71(82.3)$ & $2(2.35)$ & $1(1.2)$ & $2(2.4)$ & $75(88.2)$ \\
\hline T. Vaginalis & $3(3.5)$ & $0(0)$ & $0(0)$ & $0(0)$ & $3(3.5)$ \\
\hline G. Vaginalis & $2(2.4)$ & $0(0)$ & $0(0)$ & $0(0)$ & $2(2.4)$ \\
\hline No infection & $4(4.7)$ & $1(1.18)$ & $0(0)$ & $0(0)$ & $5(5.9)$ \\
\hline Total & $79(92.9)$ & $3(3.5)$ & $1(1.2)$ & $2(2.4)$ & $85(100)$ \\
\hline
\end{tabular}

Although it is well known that women are far from achieving equal participation in decision making especially when it comes to leadership and power as evidenced by the fact that only between 10-24 women as at 1995 and 1999 have served as heads of state and government $(20,21)$. However, from this study, it appears that women in purdah fully participate in decision making processes when it comes to reproductive health matters. This could be probably because total loyalty in purdah is not expected to the point of death from sickness. This however does not underscore the fact that some husbands in purdah do take unilateral decisions on reproductive health issues. In such cases as revealed in the structured interview, altering reproductive health decision making processes in favour of women in purdah can best be achieved by educating both these women and their husbands.

The belief that purdah system is a problem because it permits up to 3-4 wives to be secluded from taking active part in the social well-being of the community and the country (18) may actually have been misunderstood or misinterpreted by those that practice purdah. This is because Pickhall (22) stated that social degradation of women is a crime and a

\section{REFERENCES}

1. Jacobson D (1982). Studying the changing roles of women in India 8(1):132-137

libel on Islam. Pickhall (22) further claims that the unIslamic Indian style purdah system (hijab) which appears to be the type well known is a case of religion overkill. This commandment in the Qu'ran in chapter 33 verse 53 with respect to hijab applies only to the "Mothers of the Believers" (the wives of the holy Prophet, p.b.u.h) but the wordings of the Qur'an in chapter 33 verse 55, applies to all Muslim women in general. There is no screen or (hijab) (purdah) mentioned in this verse-it prescribed only a dress (22). This makes the practice of the Indian - style system of purdah unlawful.

This work concludes by stating that frantic efforts must be made to educate Muslims in purdah so as to ease some restrictions on women activities that affect particularly reproductive health. Promoting the education of Muslim women is a first step in moving beyond the constraints imposed by purdah. This struggle appears to be the only tool that will fray the threads in this socially imposed curtain.

\section{ACKNOLWDGEMENT}

We thank the Council for the Development of Social Science Research in Africa (CODESRIA) that supported this work with the grant No. 39/T99.

2. Rauf, A. (1987). Rural women of the family: A Study of Punjabi women in Pakistan Journal of corporative family 18 (13):403-415 
3. Mujlisul Ulama of South Africa (1992) The Pious Woman. Fatabran Nig. Ent. Lagos-Nigeria pp 21108.

4. Bindra, D. and Steward, J. (eds) (1971). Motivation. Hazell Watson and Viney Ltd. Great Britain pp 1113

5. Woodworth, R.S. (1971). Mechanism and Drive in: Motivation.

Hanzel Watson and Viney Ltd. Pp 66-71.

6. Rechard, J. and Barry, D. (1971). Motivation Hazell Watson and Viney Ltd. Great Britain. pp. 52-53.

7. Watts, T. E.; Larsen, S. A. and Brom, S. T. (1984). A Case Control Study of Still Births at a Teaching Hospital in Zambia 1979-80: Serological Investigations for Selected Agents. Bulletin of the WHO. 62:803-808.

8. Rosenberg, M. J.: Schilz, K.F. and Burton, N. (1986). Sexually Transmitted Diseases in Sub-Saharan Africa. Lancet 2:152

9. Meheus, A. J. and Wasserheit, J. (1991). Reproductive Tract Infections and Women's Health. A paper prepared for Conference on Reproductive Tract Infections in the 3rd World: National and International Policy Implications. Bellagio, Italy.

10. Schulz, K. F.: Schulte, J. M. and Berman, S.M. (1992). Maternal Health and Child Survival: Opportunities to Protect both Women and Children from consequences of Reproductive Infections. In: A. German; K.K. Holmes; P. Piot; J. N. Wasserheit eds. Reproductive Tract Infections: Global Impact and Priorities for Women Reproductive Health. New York, Plenum Pub. Comp.

11. Arya, O.P. and Hart, C.A.(1998). Sexually Transmitted Inflection and AIDS in the Tropics. CABI Publ. Comp. Wolling Fold UK. Pp 252-263.

12. Wasserheit, J. N. (1990). Reproductive Tract Infection. In: Special Challenges in Third World women's Health: Presentations at Annual APHA Meeting Chicago, Illinios New York: International Women Coalition.
22.

13. Bergstrom, A. (1990). Cited by Keersmakers and Meheus, A. (1998) in: Sexually Transmitted Infections and AIDS in the Tropics pp 3-30

14. Ogunbanjo, B. 0. (1989). Sexually Transmitted Diseases in Nigeria: a Review of the Present situation. West African Journal of Medicine. 8 (1): $42-49$.

15. Population Report (1993). Controlling Sexually Transmitted Disease. Series. L (9):3

16. Cheesbrough, M. (1998). Medical Laboratory Manual for Tropical Countries Vol II Butterwoth Hernemen Oxford.

17. Wasserheit, J.N. (1989). Cited by Keermaker, K and Maheus, A. (1998). In: Epidemiology of Sexually Transmitted Infection and AIDs in the Tropics pp 3-30.

18. Uduigwomen, A.F. (2004). A Philosophy of Education for Nigerian

Women: Problems and Prospects. The African Symposium 4(1):

21-27.

19. Oomman, N. (1998). Sexuality: Not Just a Reproductive Health Matter. Reproductive Health Matters. 6(12): 10-16

20. Anonymous (2000). Women in Power and Decision-Making. Gender Equality, Development and Peace for the Twenty First Century. New York, pp 5-9.

21. Corner, L (1997). Women's Participation in Decision-Making and

Leadership: A global Perspective. Technical Paper delivered at Asian

Women in Co-operative Development (ACWF) and International Cooperative alliance Regional Office for the Pacific (KAROAP).

Pickthall, M. (1927). Social Degradation of Women- a Crime and a Libel on Islam. Lecture Series delivered in Madras. 